\title{
'WhipperSnapper', a Dual-purpose Southernpea for the Production of Both Snaps and Fresh-shell Peas
}

\author{
Richard L. Fery ${ }^{2}$ \\ U.S. Vegetable Laboratory, Agricultural Research Service, U.S. Department \\ of Agriculture, 2700 Savannah Highway, Charleston, SC 29414-5334 \\ Blair Buckley \\ Red River Research Station, Louisiana Agricultural Experiment Station, LSU \\ AgCenter, P.O. Box 8550, Bossier City, LA 71113-8550
}

Dyremple B. Marsh ${ }^{1}$

Lincoln University Cooperative Research, Jefferson City, MO 65102-0029

Additional index words. Vigna unguiculata, cowpea, vegetable breeding

'WhipperSnapper' is a new southernpea [Vigna unguiculata (L.) Walp.] released 13 Jan. 2006 by the Agricultural Research Service of the U.S. Department of Agriculture, the LSU AgCenter, and Lincoln University. The new cultivar is the product of a breeding program to incorporate the superior yield and seed characteristics of Asian "vegetable cowpeas" into American snap-type southernpeas. Traditionally, home gardeners and farmers in the southern United States have grown southernpeas to produce both freshshell peas and immature, fresh pods or snaps. Southernpeas are tolerant to drought and hot weather and can be grown quite successfully under conditions that are totally unsuitable for such table legumes as the common bean (Phaseolus vulgaris L.). 'WhipperSnapper' was developed for use as a dual-purpose cultivar that can be used to produce both snaps and fresh-shell peas.

\section{Origin}

'WhipperSnapper' is the product of a pedigree-type breeding program initiated in 1988. The initial cross involved UCR-204 and 87-161-2. UCR-204 is a snap-type cowpea germplasm line released by the University of California at Riverside in 1986 (Patel and Hall, 1986); it was developed at the Indian Agricultural Research Institute, New Delhi, India, and was evaluated in India as breeding line No. 779. UCR-204 is an early maturing, photo-insensitive, and high-yielding line, but its pods exhibit a considerably lighter green color than is traditional for U.S. snap cultivars. Also, UCR-204 seeds

\footnotetext{
Received for publication 20 Oct. 2006. Accepted for publication 11 Nov. 2006

The technical assistance of F. P. Maguire is gratefully acknowledged.

${ }^{1}$ Current address: College of Agriculture and Related Sciences, Delaware State University, 1200 N. DuPont Highway, Dover, DE 19901-2277. ${ }^{2}$ To whom reprint requests should be addressed; e-mail Richard.Fery@ars.usda.gov
}

yellow. Pods are borne above the foliage. Ready-to-harvest pods are attached to the peduncles in a pendant manner. Each peduncle most commonly produces two pods, but the cultivar has a tendency to produce greater numbers of pods per peduncle in some seasons. In a 2001 planting, for example, $36 \%$ of the 'WhipperSnapper' peduncles produced three pods, $6 \%$ produced four pods, and $1 \%$ produced five pods. Typical ready-to-harvest 'WhipperSnapper' snaps are green colored and slightly curved at the attachment end. Typical mature-green pods suitable for freshshell harvest exhibit an attractive yellow color, are $25 \mathrm{~cm}$ long, and contain $\approx 14$ seeds (Fig. 1). The hulls of the mature-green pods are loose around the peas and the constrictions are distinct (pea locations in unshelled pods are quite obvious). Mature-green pods shell easily. Fresh peas are cream-colored, kidney-shaped, and weigh 24.5 g per 100 peas. Dry pods exhibit a light straw color. Dry peas have a smooth seedcoat.

Replicated dry pod harvest field studies have a brown eye color pattern rather than the solid cream color pattern that is traditional for U.S. snap cultivars. The paternal parent $87-$ 161-2 is a sister line of the snap-type cultivar 'Bettersnap', which was released by the U.S. Department of Agriculture in 1994 (Fery and Dukes, 1995). 'WhipperSnapper' originated from a bulked $F_{8}$ population grown in 1996. It was evaluated as US-905 throughout the southern United States as an entry in the 1998, 1999, and 2000 Regional Southernpea Cooperative Trials.

\section{Description}

'WhipperSnapper' has a compact, erect plant habit. The leaf color is a dull medium green and the leaf surface is smooth. There is no red or purple pigmentation on stems, branches, petioles, or peduncles. Flower color is white, but the back and the lower center portion of the inside of the standard are were conducted at Charleston, SC, in 1997 , 1998, 2000, and 2001 to compare the maturity, seed size, and yield characteristics of 'WhipperSnapper' and 'Bettersnap' (Table 1). The results of these studies indicated that 'WhipperSnapper', on average, is 2.7 d earlier than 'Bettersnap', produces seeds that are $7.1 \%$ smaller ( 9.2 g per 100 dry seed), and has a $19 \%$ greater yield potential. Additionally, the results of these studies clearly indicated that the quality of 'WhipperSnapper' seed is excellent and much superior to that of 'Bettersnap'. 'Bettersnap' seedcoats have a tendency to split, and this undesirable trait, in addition to being a seed production problem for seedsmen, limits the usefulness of 'Bettersnap' as either a fresh-shell or dry-shell cultivar.

A replicated field study was conducted at Charleston, SC, in 1999 to compare the maturity, pod, and yield characteristics of 'WhipperSnapper' and 'Bettersnap' when

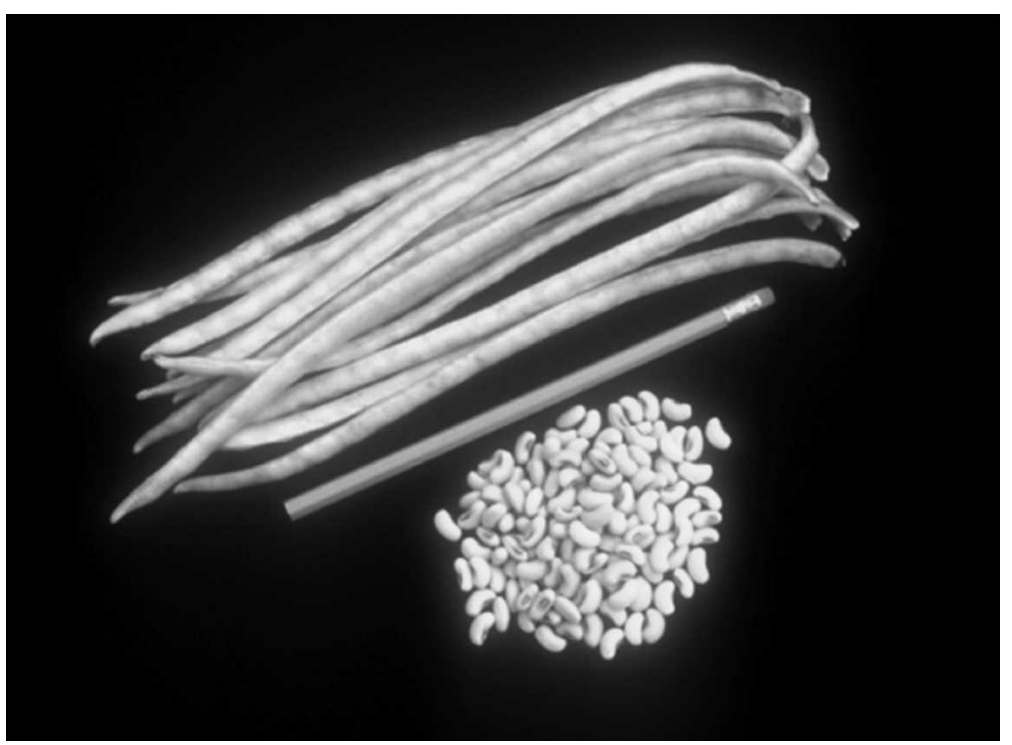

Fig. 1. Mature-green pods and fresh-shell peas of 'WhipperSnapper' southernpea. Note the long, straight pods and the solid-colored (cream), kidney-shaped peas. Mature-green 'WhipperSnapper' pods exhibit an attractive yellow color and are extremely easy to shell. 
Table 1. Number of days to dry pod harvest, weight per 100 dry peas, and dry pea yield for WhipperSnapper and Bettersnap southernpeas grown in spring trials, Charleston, SC, 1997, 1998, 2000 , and 2001. ${ }^{\mathrm{z}}$

\begin{tabular}{|c|c|c|c|}
\hline Trial/Cultivar & $\begin{array}{l}\text { Days to dry } \\
\text { pod harvest } \\
\text { (no.) }\end{array}$ & $\begin{array}{c}\mathrm{Wt} / 100 \\
\text { dry peas }(\mathrm{g})\end{array}$ & $\begin{array}{c}\text { Dry pea yield } \\
\left(\mathrm{kg} \cdot \mathrm{ha}^{-1}\right)\end{array}$ \\
\hline \multicolumn{4}{|l|}{ Trial 1, 1997} \\
\hline WhipperSnapper & $65.0 \mathrm{~b}^{\mathrm{y}}$ & $8.6 \mathrm{~b}$ & $1018 \mathrm{a}$ \\
\hline Bettersnap & $66.6 \mathrm{a}$ & $10.6 \mathrm{a}$ & $601 \mathrm{~b}$ \\
\hline \multicolumn{4}{|l|}{ Trial II, 1998} \\
\hline WhipperSnapper & $58.6 \mathrm{~b}$ & $9.8 \mathrm{~b}$ & $738 \mathrm{a}$ \\
\hline Bettersnap & $60.9 \mathrm{a}$ & $11.9 \mathrm{a}$ & $751 \mathrm{a}$ \\
\hline \multicolumn{4}{|l|}{ Trial III, 2000} \\
\hline WhipperSnapper & $64.0 \mathrm{~b}$ & $9.0 \mathrm{~b}$ & $620 \mathrm{a}$ \\
\hline Bettersnap & $67.8 \mathrm{a}$ & $11.6 \mathrm{a}$ & $545 \mathrm{a}$ \\
\hline \multicolumn{4}{|l|}{ Trial IV, 2001} \\
\hline WhipperSnapper & $65.0 \mathrm{~b}$ & $8.6 \mathrm{~b}$ & $531 \mathrm{a}$ \\
\hline Bettersnap & $67.6 \mathrm{a}$ & $10.4 \mathrm{a}$ & $386 \mathrm{a}$ \\
\hline \multicolumn{4}{|c|}{ Combined analysis of all trials } \\
\hline WhipperSnapper & $62.5 b^{\mathrm{NS}}$ & $9.2 \mathrm{~b}^{\mathrm{NS}}$ & $714 a^{* *}$ \\
\hline Bettersnap & $65.2 \mathrm{a}$ & $11.3 \mathrm{a}$ & $598 \mathrm{~b}$ \\
\hline
\end{tabular}

${ }^{\mathrm{z}}$ Spring 1997, 1998, 2000, and 2001 trials planted on 2 June, 27 May, 1 June, and 5 June, respectively. The experimental design of each trial was a randomized complete block with five $(1997,2001)$ or 10 replications $(1998,2000)$. Each plot was space-planted, 18 hills per plot, three seeds per hill, $30 \mathrm{~cm}$ between hills, and $102 \mathrm{~cm}$ between rows. Results of combined analyses of all trials indicated a significant cultivar $\times$ trial interaction for dry pea yield. Consequently, results are presented for both single trial and combined analyses to aid interpretation.

${ }^{\mathrm{y}}$ Mean separation within columns and trials by the Student-Newman-Keuls multiple range test, $P \leq 0.05$. ${ }^{\mathrm{NS}, * *}$ Nonsignificant or significant interaction between cultivar and trial at $P \leq 0.01$.

Table 2. Number of days to harvest, pod length, pod diameter, and fresh pod (snap) yield for WhipperSnapper and Bettersnap southernpeas grown in a spring trial, Charleston, SC, $1999 .^{\text {z }}$

\begin{tabular}{|c|c|c|c|c|c|}
\hline \multirow[b]{2}{*}{ Cultivar } & \multirow{2}{*}{$\begin{array}{l}\text { Days to first } \\
\text { harvest (no.) }\end{array}$} & \multicolumn{2}{|c|}{ Pod diam } & \multirow{2}{*}{$\begin{array}{l}\text { Pod length } \\
\quad(\mathrm{cm})\end{array}$} & \multirow{2}{*}{$\begin{array}{l}\text { Fresh pod (snap) yield } \\
\qquad\left(\mathrm{kg} \cdot \mathrm{ha}^{-1}\right)\end{array}$} \\
\hline & & Width (mm) & $\mathrm{Ht}(\mathrm{mm})$ & & \\
\hline WhipperSnapper & $49.4 \mathrm{a}^{\mathrm{y}}$ & $6.37 \mathrm{a}$ & $7.64 \mathrm{a}$ & $24.0 \mathrm{a}$ & $10,468 \mathrm{a}$ \\
\hline Bettersnap & $50.0 \mathrm{a}$ & $6.46 \mathrm{a}$ & $7.53 \mathrm{a}$ & $23.4 \mathrm{a}$ & $6,474 \mathrm{~b}$ \\
\hline
\end{tabular}

${ }^{z}$ Trial planted on 2 June 1999. The experimental design was a randomized complete block with 10 replications. Each plot was space-planted, 18 hills per plot, three seeds per hill, $30 \mathrm{~cm}$ between hills, and $102 \mathrm{~cm}$ between rows. The trial was harvested on 21 July, 23 July, 25 July, 28 July, 30 July, and 2 Aug. Each harvest was planned so that most of the harvested fresh pods were commercial sieve size no. 2 (5.75 to $7.34 \mathrm{~mm}$ in width).

${ }^{\mathrm{y}}$ Mean separation within columns by the Student-Newman-Keuls multiple range test, $P \leq 0.05$.

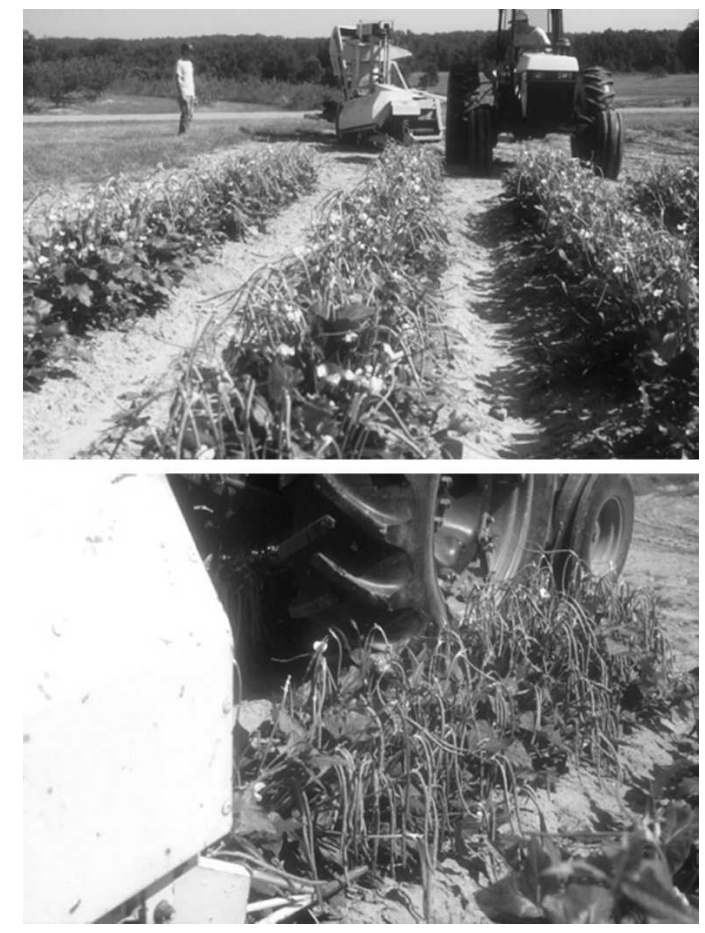

Fig. 2. Field planting of 'WhipperSnapper' southernpeas at "snap-stage" maturity being harvested by a commercial reel-type snap-bean harvester in Calhoun, LA. Note the compact, erect plant habit and the long, straight snaps. harvested as snaps (Table 2). The study was seeded on 2 June, and predominantly sieve size No. 2 snaps ( 5.75 to $7.34 \mathrm{~mm}$ in width) (Robinson et al., 1963) were harvested five times between 21 July and 2 Aug. The average date to first harvest for 'WhipperSnapper' was $49.4 \mathrm{~d}$ ( $0.6 \mathrm{~d}$ earlier than 'Bettersnap'). The average width $(6.37 \mathrm{~mm})$, height $(7.64$ $\mathrm{mm})$, and length $(24 \mathrm{~cm})$ of 'WhipperSnapper' pods were not significantly different from those of 'Bettersnap' pods. However, the total 'WhipperSnapper' yield of snaps $\left(10,468 \mathrm{~kg} \cdot \mathrm{ha}^{-1}\right)$ was $62 \%$ greater than the total 'Bettersnap' yield of snaps. In 2000, an unreplicated field study was conducted at Jefferson City, MO, to evaluate the potential of 'WhipperSnapper' to produce snaps. This study, planted on 3 June and harvested 12 times between 21 Aug. and 20 Sept., produced a total snap yield $\left(9514 \mathrm{~kg} \cdot \mathrm{ha}^{-1}\right)$, similar to that observed in the Charleston, SC, study.

Replicated field studies conduced at Calhoun, LA, in 1999, 2000, and 2001 demonstrated that a commercial reel-type snap-bean harvester can be used to mechanically harvest snaps from 'WhipperSnapper' plants (Fig. 2). The yields produced by this single-harvest mechanized procedure were relatively consistent from year to year (average snap yield of $1111 \mathrm{~kg} \cdot \mathrm{ha}^{-1}$ ).

'WhipperSnapper' is recommended for use by home gardeners for production of both snaps and fresh-shell peas. The new cultivar produces abundant quantities of snaps during seasons too hot for successful culture of snapbean cultivars. The mature-green pods are long, exhibit an attractive yellow color, and are extremely easy to shell. The ease-ofshelling trait is important to home gardeners because most home gardeners must shell their harvest by hand. 'WhipperSnapper' is also recommended for trial by market gardeners to produce snaps, mature-green pods, and fresh-shell peas for sale in farmers' markets. Additionally, 'WhipperSnapper' has potential as a mechanically harvested source of snaps for use by food processors in mixed packs of peas and snaps.

\section{Availability}

Protection for 'WhipperSnapper' is being sought under the Plant Variety Protection Act. Genetic material of this release will be deposited in the National Plant Germplasm System, where it will be available for research purposes, including the development and commercialization of new cultivars. It is requested that appropriate recognition of source be given when this germplasm contributes to research or development of a new breeding line or cultivar.

\section{Literature Cited}

Fery, R.L. and P.D. Dukes. 1995. 'Bettersnap' southernpea. HortScience 30:1318-1319.

Patel, P.N. and A.E. Hall. 1986. Registration of snap-cowpea germplasms. Crop Sci. 26:207. Robinson, W.B., D.E. Wilson, J.C. Moyer, J.D. Atkin, and D.B. Hand. 1963. Quality versus yield of snap beans for processing. Proc. Amer. Soc. Hort. Sci. 84:339-347. 